\title{
The morality of attitudes toward nanotechnology: about God, techno-scientific progress, and interfering with nature
}

\author{
Frederic Vandermoere $\cdot$ Sandrine Blanchemanche • \\ Andrea Bieberstein · Stephan Marette • \\ Jutta Roosen
}

Received: 13 July 2009/Accepted: 16 November 2009/Published online: 28 November 2009

(C) Springer Science+Business Media B.V. 2009

\begin{abstract}
Using survey data, we examine public attitudes toward and awareness of nanotechnology in Germany $(N=750)$. First, it is shown that a majority of the people are still not familiar with nanotechnology. In addition, diffusion of information about nanotechnology thus far mostly seems to reach men and people with a relative higher educational background. Also, pro-science and technology views are positively related with nanotech familiarity. Results further show that a majority of the people have an indifferent, ambiguous, or non-attitude toward nanotechnology. Multinomial logit analyses further reveal
\end{abstract}

\section{F. Vandermoere $(\bowtie)$}

Harvard Kennedy School, Program on Science,

Technology and Society, Cambridge, MA, USA

e-mail: Frederic_Vandermoere@hks.harvard.edu

F. Vandermoere

Department of Sociology, Ghent University, Korte Meer

5, 9000 Ghent, Belgium

S. Blanchemanche

Metarisk Department, INRA Paris, Paris, France

\section{A. Bieberstein}

Marketing und Konsumforschung, Technische Universität

München, München, Germany

S. Marette

UMR Économie publique, INRA, Paris, France

J. Roosen

Lehrstuhl für BWL - Marketing und Konsumforschung,

Technische Universität München, München, Germany that nanotech familiarity is positively related with people's attitudes. In addition, it is shown that traditional religiosity is unrelated to attitudes and that individual religiosity is weakly related to nanotechnology attitudes. However, moral covariates other than religiosity seem of major importance. In particular, our results show that more negative views on technological and scientific progress as well as more holistic views about the relation between people and the environment increase the likelihood of having a negative attitude toward nanotechnology.

Keywords Nanotechnology · Religiosity · Attitudes · Public understanding - Risk perception · Societal implications

\section{Introduction}

Next to benefits, the success of new technologies increasingly depends on safety assessments and risk perceptions. However, in their report on ethical issues raised by nanotechnology, the French National Advisory Committee on Ethics (CCNE) reminded us that $<0.5 \%$ of the global nanotechnology research budget is spent on risk assessments (Ameisen et al. 2007). This lack of expert knowledge may not only cause a state of regulatory alienation and institutional risks (cf. Rothstein et al. 2006), but it may also induce new threats to the environment, people's health and the social order (Roco and Bainbridge 2001). 
Previous research has shown that people may be supportive toward nanotechnology (Bainbridge 2002) and suggested that positive perceptions relate to higher levels of self-reported knowledge (Cobb and Macoubrie 2004). However, previous studies have also shown that attitudes regarding nanotechnology relate to socio-cultural factors such as religion, trust in governmental agencies, antiscientist feelings, and pro-technology orientations (Cobb and Macoubrie 2004; Kahan et al. 2009; Pidgeon et al. 2009; Scheufele et al. 2009).Within this context, this study examines the determinants of public attitudes toward nanotechnology with specific attention for moral covariates such as religious beliefs, thoughts about techno-scientific progress, and views on interference with nature, and after this it is controlled for familiarity with nanotechnology.

Previous research on attitudes toward nanotechnology has mainly focussed on cognitive and emotional processes (Brossard et al. 2009). With regard to the cognitive, descriptive results on the public understanding of nanotechnology have shown that about half of the population are not aware of the existence of nanotechnology and that people's knowledge about nanotechnology is low to very low (Cobb and Macoubrie 2004; Lee et al. 2005; Waldron et al. 2006; Kahan et al. 2009). Moreover, within the US context, these low levels of public knowledge about nanotechnology have remained relatively constant since 2004 (Scheufele et al. 2009). Further, at the explanatory level, the familiarity hypothesis has often been postulated, i.e., the assumption that support for new technologies is positively related with familiarity. Research has shown, however, that nanotech literacy has no direct impact on attitudes toward nanotechnology (Cobb and Macoubrie 2004; Scheufele and Lewenstein 2005; Brossard et al. 2009). On the other hand, if people's self-estimated (rather than actual) knowledge is high, they are more likely to perceive the benefits as outweighing the risks (Cobb and Macoubrie 2004). Further, in an experimental study by Kahan et al. (2009) the familiarity hypothesis was refuted because findings showed that a pro-technology orientation predisposed people to learn more about nanotechnology. Therefore, this study will begin with an examination of the association between moral variables and familiarity with nanotechnology.
Next to knowledge variables, several authors have pointed to the role of heuristics (see, e.g., Tversky and Kahneman 1974; Kahan et al. 2009). For example, research has indicated the role of science media use as well as trust as a coping mechanism when knowledge is low (Scheufele and Lewenstein 2005; Luhmann 1989). In addition, US research suggested that the significance of religion and thoughts about the desirability of creating life without godlike intervention. First, at the individual level, some studies have revealed a negative association between support for funding of nanotechnology and levels of religiosity, and suggested that the familiarity hypothesis only applies to less religious people (Brossard et al. 2009). Second, at the country-level, a negative relation has been identified between aggregate levels of religiosity and support for nanotechnology (Scheufele et al. 2009). Specifically, countries with a relative strong religious climate such as the United States, Ireland, and Italy seemed to be less likely to morally accept nanotechnology than more secularized states such as Denmark, Sweden, France, and Germany (Scheufele et al. 2009).

In this article, we built on these previous US studies by examining the role of religiosity in Germany. Within a Western European perspective, Germany is characterized by medium to high levels of secularization (Wolf 2008). Therefore, we expect that religiosity will be less important in Germany, a state which is relatively more secularized than the United States (cf. Norris and Inglehart 2004). Further, we will look if attitudes toward nanotechnology can be explained by moral covariates other than religion. First, as research has shown that egalitarian perspectives and more negative views on science might induce people to think that the risks of nanotechnology will outweigh the benefits (Cobb and Macoubrie 2004; Kahan et al. 2009), we will examine the importance of normative thoughts about technoscientific progress. Second, it has been noted previously that views on tampering with nature and unnatural threats is an important yet largely forgotten determinant of risk perceptions and attitudes (Sjöberg 2000a, b). As such, next to familiarity, religiosity and normative views on science and technology, we will examine the extent to which the variation in nanotech attitudes can be explained by different views on nature interference. Before we discuss the results, we 
will clarify the study design and the measures in the next section.

\section{Method and measures}

Study design and participants

Data were collected from within Germany by means of a web survey between February and April 2009. Germany is the leading country in nanotechnology in Europe in terms of $\mathrm{R} \& \mathrm{D}$ expenditure (European Commission 2005). Persons over 18 years of age received an invitation letter and the link to the questionnaire by e-mail. Although web surveys may provide many advantages, it has been acknowledged previously that most web surveys are not able to employ random samples (Bainbridge 2002). In order to minimize potential problems associated with the extrapolation of the results, the quota sampling method was used with the variables gender, age, education, and region (see appendix: Table 5). Seven hundred and fifty people participated in the study $(N=750)$. The age of the respondents ranged from 18 to 89 years, with an average age of 45 years. Fifty-one percent $(n=382)$ of the respondents were male and forty-nine percent $(n=368)$ were female. The educational background of the participants ranged from no education $(0.7 \%, n=5)$, a certificate of secondary education $(45.7 \%, n=343)$, a qualification to enter vocational or higher education $(27.3 \%$, $n=205)$, a qualification to enter advanced technical college $(6.7 \%, n=50)$, to a general qualification for university entrance $(19.6 \%, n=147)$.

\section{Measures}

Familiarity with nanotechnology was measured by asking the participants if they had ever heard about nanotechnology (with $0=$ no and $1=$ yes). We then asked those people that mentioned an awareness of the existence of nanotechnology about their knowledge of nanotechnology. Self-estimated knowledge was measured by the question, "To what extent do you feel informed about nanotechnology?" Scores ranged from 1 (little knowledge) to 10 (a lot of knowledge). People were considered "unfamiliar" when they reported no knowledge or just a little knowledge (score 3 or less on self-reported knowledge) and "familiar" when they reported moderate knowledge or a lot of knowledge (score 4 or more on self-estimated knowledge; see Table 1). Subsequently, the following description of nanotechnology was given.

Nanotechnology refers to materials, systems, and processes which exist or operate in the range of about 1-100 nanometers $(\mathrm{nm})$. One nanometer $(\mathrm{nm})$ is one millionth of a millimetre $(\mathrm{mm})$. It involves the creation of structures and systems on the scale of atoms and molecules, the nanoscale. Materials at the nanoscale show novel properties that lead to novel applications in diverse fields like medicine, cosmetics, biotechnology, energy production, and environmental science. The same novel properties that may provide benefits relate to uncertainty regarding how nanomaterials may interact with human health and the environment.

Attitudes toward nanotechnology were then measured by questioning "How would you describe your opinion about nanotechnology?" with " $1=$ rather positive," " $2=$ rather negative," and " $3=$ not positive, nor negative."

The role of religion was measured by three questions. First, traditional religiosity was measured by questioning "Are you an active member of a church or religious organization?" (yes/no). Second, to distinguish individual religiosity from traditional religiosity (cf. Wolf 2008), individual religiosity was measured by questioning "How important is religion in your life?" (scores ranged from $1=$ "not important at all" to $10=$ "extremely important"). Third, the role of spirituality (cf. e.g., Heelas and Woodhead

Table 1 Frequencies and percentages: nanotech familiarity and attitudes $(N=750)$

\begin{tabular}{lc}
\hline & $\%(n)$ \\
\hline Familiarity nanotechnology & \\
Unfamiliar & $66.4(498)$ \\
No knowledge & $39.7(298)$ \\
Low knowledge & $26.7(200)$ \\
Familiar & $33.6(252)$ \\
Moderate knowledge & $25.9(194)$ \\
High knowledge & $7.7(58)$ \\
Attitudes toward nanotechnology & \\
Rather positive & $20.3(152)$ \\
Rather negative & $21.9(164)$ \\
Not positive, nor negative & $57.9(434)$ \\
\hline
\end{tabular}


2005) was measured by questioning "Which of these statements comes closest to your beliefs? (a) I believe there is a God, (b) I believe there is some sort of spirit or life force, or (c) I do not believe there is any sort of spirit, God or life force."

We measured views on science and technology by asking, "All things considered, would you say that the world is better off, or worse off because of science and technology?" Scores ranged from 1 (the world is a lot worse off) to 10 (the world is a lot better off).

Views on nature were measured by the human interdependence scale as developed by Corral-Verdugo et al. (2008). The latter consists of five items and examines the extent to which people view human progress as dependent on the preservation of nature (e.g., preserving nature now means ensuring the future of human beings). Scores ranged from 1 (totally disagree) to 5 (totally agree) (alpha $=0.877$ ). As nanotechnology relates to the creation of nature and innovation, rather than to nature conservation and stability, we presumed that higher scores on this scale relate to more negative attitudes toward nanotechnology.

\section{Analysis}

In a first section of the analysis, we will examine the predictors of familiarity with nanotechnology by using binary logistic regression analysis. In a section part, we will focus on the determinants of attitudes toward nanotechnology in general. As the dependent variables "attitudes" consists of three ordered categories, several options for analysis are available. The first choice is ordered regression yet analyses showed that the parallel regression assumption was violated (i.e., the coefficients were not constant across the categories of the dependent variable). A second choice was binary logistic regression yet analyses revealed that the recoding of the dependent variable into two categories resulted in an overestimation or underestimation of some of the parameters (e.g., between familiarity and attitudes). As such, multinomial regression analyses were used to address differences between positive attitudes, negative attitudes, and non-attitudes. Partially standardized logit coefficients were calculated to know the relative strength of the independent variables on the dependent variables (cf. Agresti 1996).

\section{Results}

In this sample, several people were not aware of or familiar with nanotechnology. Before they looked at the survey, 39.7\% ( $n=298)$ had never heard about it (see Table 1). Of those people that had heard about nanotechnology $(60.3 \%, n=452), 26.7 \%(n=200)$ had little knowledge, $25.9 \%$ had moderate knowledge $(n=194)$, and only $7.7 \%$ reported having a lot of knowledge $(n=58)$. In other words, two-thirds of the German public, or $66.4 \%$ (498/750), is unfamiliar with nanotechnology. These results are similar to previous findings reported in the literature (see, e.g., Waldron et al. 2006).

The likelihood of being familiar with nanotechnology was further assessed by using binary logistic regression analysis. The results presented in Table 2 shows that for men, relative to women, the odds ratio of being familiar with nanotechnology is expected to increase by a factor of 1.92. In other words, females are almost twice as likely than males to be unfamiliar with nanotechnology. The age of the respondents is not significantly related to nanotechnology familiarity. Further, educational background is positively related to familiarity with nanotechnology. For people with a higher education compared to lower educated people, the odds ratio of being familiar with nanotechnology is expected to increase by a factor of 1.29 when the other social demographics are held constant. Considering educational background as a proxy for socio-economic position, the diffusion of

Table 2 Social-demographic and moral determinants of selfreported familiarity with nanotechnology $(N=750)$

\begin{tabular}{lllr}
\hline Independents & $B(\mathrm{SE})$ & $\operatorname{Exp}(B)$ & \multicolumn{1}{l}{$B s^{\prime}$} \\
\hline Gender & $0.654 * *(0.164)$ & 1.924 & 0.327 \\
Age & $-0.005(0.006)$ & 0.995 & -0.075 \\
Education & $0.253 * * *(0.071)$ & 1.288 & 0.291 \\
Science and technology & $0.094 *(0.042)$ & 1.099 & 0.189 \\
Nature interference & $0.016(0.023)$ & 1.016 & 0.058 \\
Nagelkerke $R^{2}$ & $8.3 \%$ & & \\
\hline
\end{tabular}

$* p<0.05, * * p<0.01, * * * p<0.001$

Note: Binary logistic regression; unfamiliar $=0$ and familiar $=1$; $\quad$ reference $\quad$ category gender $=$ female; $B=$ unstandardized logistic coefficients; $B s^{\prime}=$ partially standardized logistic coefficients, i.e., a change of 1 standard deviation in the predictor is associated with a change of $B s^{\prime}$ in logit (familiarity) 
information about nanotechnology thus far mostly seems to reach men and people from the middle to upper socio-economic groups. Further, views on interfering with nature are unrelated to familiarity. However, pro-science and technology views are positively related to familiarity. This is consistent with previous research that has shown that a protechnology orientation can predispose people to learn more about nanotechnology (Kahan et al. 2009). The partially standardized logit coefficients further indicate that the strongest correlate of familiarity with nanotechnology is gender $\left(B s^{\prime}=0.327\right)$, followed by education $\left(B s^{\prime}=0.291\right)$, and science and technology views $\left(B s^{\prime}=0.189\right)$.

Further, once they received information on nanotechnology (cf. Methods section), 57.9\% of the respondents described their opinion toward nanotechnology as "not positive, nor negative" (see Table 1). In other words, a majority of the people hold an ambiguous position, they have an indifferent attitude, or they did not already form an opinion. Among those people that have a more pronounced opinion $(42.2 \%, n=316)$, half of the people have a rather positive attitude $(48.1 \%, 152 / 316)$ and half of them have a rather negative attitude $(51.9 \%, 164 /$ 316).

The likelihood of having a negative rather than a positive attitude toward nanotechnology, and a nonattitude rather than a positive or negative attitude, was further assessed by using multinomial logistic regression analyses (see Tables 3, 4). The results presented in the first two models in Table 3 show that church membership and self-reported importance of religion in life are unrelated to nanotech attitudes. People that believe in God are more likely than those that do not to form an opinion about nanotechnology, whether it will be positive or negative (cf. models 3B and 3C). However, belief in God does not differentiate positive and negative attitudes toward nanotechnology (cf. model 3A). Further, the effect of belief in God on "negative versus neutral attitudes" is partially mediated by the other moral covariates (cf. differences between models 3C and 4C). In particular, pro-science and technology attitudes and nature interference mediate $17 \%$ of the effect of religious beliefs [ $(0.601-0.496) / 0.601]$.

The results presented in Table 4 show that men are more likely to have a positive attitude toward nanotechnology than women. Age has no significant effect on people's attitudes (see models 4A, 4B, and $4 \mathrm{C}$ : the odds ratio's are very close to 1 ). For people with a higher education compared to lower educated people, the odds ratio of being positive rather than neutral toward nanotechnology is expected to increase by a factor of 1.24 (cf. model 4B). Furthermore, the effects of both gender and education are partially mediated by self-reported familiarity with nanotechnology (cf. model 5). In particular, familiarity with nanotechnology mediates $13 \%$ of the effect of gender on positive versus negative attitudes toward nanotechnology [(0.949-0.822)/0.949]. In addition, nanotech familiarity mediates $29 \%$ of the effect of education on positive versus neutral attitudes toward nanotechnology [(0.214-0.151)/0.214].

Table 3 Religiosity and attitudes toward nanotechnology $(N=750)$

\begin{tabular}{|c|c|c|c|c|c|c|c|c|c|c|}
\hline \multirow[t]{2}{*}{ M } & \multirow[t]{2}{*}{ IV } & \multicolumn{3}{|c|}{ Positive vs. negative (A) } & \multicolumn{3}{|c|}{$\begin{array}{l}\text { Positive vs. not positive, } \\
\text { nor negative (B) }\end{array}$} & \multicolumn{3}{|c|}{ Negative vs. not positive, nor negative (C) } \\
\hline & & $B(\mathrm{SE}) \mathrm{sig}$ & $\operatorname{Exp}(B)$ & $B s^{\prime}$ & $B(\mathrm{SE}) \mathrm{sig}$ & $\operatorname{Exp}(B)$ & $B s^{\prime}$ & $B$ (SE) sig & $\operatorname{Exp}(B)$ & $B s^{\prime}$ \\
\hline 1 & Religion 1 & $0.150(0.250)$ & 1.162 & 0.068 & $0.333(0.209)$ & 1.395 & 0.150 & $0.183(0.205)$ & 1.201 & 0.082 \\
\hline 2 & Religion 2 & $0.009(0.037)$ & 1.009 & 0.028 & $0.029(0.031)$ & 1.030 & 0.090 & $0.021(0.030)$ & 1.021 & 0.065 \\
\hline \multirow[t]{3}{*}{3} & Religion 3 & & & & & & & & & \\
\hline & Atheïst & $0.061(0.283)$ & 1.063 & 0.029 & $-0.539 *(0.234)$ & 0.583 & -0.259 & $-0.601 * *(0.227)$ & 0.548 & -0.288 \\
\hline & Spiritual & $-0.007(0.282)$ & 0.993 & -0.003 & $-0.191(0.242)$ & 0.826 & -0.086 & $-0.184(0.225)$ & 0.832 & -0.083 \\
\hline
\end{tabular}

$* p<0.05, * * p<0.01, * * * p<0.001$

Note: Multinomial logistic regression $(N=750)$. M (=Model), IV (=Independent variable), $B=$ unstandardized logistic coefficients, $B s^{\prime}=$ partially standardized logistic coefficients, Religion $1=$ membership of a church or religious organization, Religion 2 = importance of religion in life, Religion $3=$ belief in God, spirit or life force, ref. category Religion $3=$ belief in God, the effects of the religiosity measures in Model 1,2, and 3 are controlled for social-demographic characteristics 
Table 4 Attitudes toward nanotechnology: moral covariates and self-reported familiarity $(N=750)$

\begin{tabular}{|c|c|c|c|c|c|c|c|c|c|c|}
\hline \multirow[t]{2}{*}{ M } & \multirow[t]{2}{*}{ IV } & \multicolumn{3}{|c|}{ Positive vs. negative (A) } & \multicolumn{3}{|c|}{$\begin{array}{l}\text { Positive vs. not positive, nor } \\
\text { negative (B) }\end{array}$} & \multicolumn{3}{|c|}{$\begin{array}{l}\text { Negative vs. not positive, nor } \\
\text { negative }(\mathrm{C})\end{array}$} \\
\hline & & $B(\mathrm{SE}) \operatorname{sig}$ & $\begin{array}{l}\operatorname{Exp} \\
(B)\end{array}$ & $B s^{\prime}$ & $B(\mathrm{SE})$ sig & $\begin{array}{l}\operatorname{Exp} \\
(B)\end{array}$ & $B s^{\prime}$ & $B(\mathrm{SE}) \mathrm{sig}$ & $\begin{array}{l}\operatorname{Exp} \\
(B)\end{array}$ & $B s^{\prime}$ \\
\hline \multirow[t]{8}{*}{4} & Gender & $-0.949 * * *(0.251)$ & 0.387 & -0.475 & $-0.758(0.209)^{* * *}$ & 0.469 & -0.379 & $0.191(0.195)$ & 1.210 & 0.096 \\
\hline & Age & $-0.015(0.008)$ & 0.986 & -0.225 & $-0.006(0.007)$ & 0.994 & -0.090 & $0.008(0.007)$ & 1.008 & 0.120 \\
\hline & Education & $0.136(0.107)$ & 1.146 & 0.156 & $0.214 *(0.086)$ & 1.238 & 0.246 & $0.078(0.090)$ & 1.081 & 0.090 \\
\hline & S\&T & $0.422 * * *(0.067)$ & 1.525 & 0.848 & $0.247 * * *(0.057)$ & 1.280 & 0.496 & $-0.175^{* * *}(0.049)$ & 0.839 & -0.352 \\
\hline & Nature & $-0.177 * * *(0.038)$ & 0.838 & -0.644 & $-0.014(0.028)$ & 0.986 & -0.051 & $0.163 * * *(0.031)$ & 1.117 & 0.593 \\
\hline & Religion 3 & & & & & & & & & \\
\hline & Atheïst & $-0.043(0.298)$ & 0.958 & -0.021 & $-0.539 *(0.240)$ & 0.583 & -0.259 & $-0.496 *(0.235)$ & 0.609 & -0.239 \\
\hline & Spiritual & $-0.040(0.294)$ & 0.961 & -0.018 & $-0.202(0.246)$ & 0.817 & -0.091 & $-0.162(0.232)$ & 0.850 & -0.073 \\
\hline \multirow[t]{9}{*}{5} & Gender & $-0.822 * *(0.257)$ & 0.439 & -0.411 & $-0.657 * *(0.214)$ & 0.518 & -0.329 & $0.165(0.197)$ & 1.179 & 0.083 \\
\hline & Age & $-0.015(0.009)$ & 0.986 & -0.225 & $-0.007(0.007)$ & 0.933 & -0.105 & $0.008(0.007)$ & 1.008 & 0.120 \\
\hline & Education & $0.066(0.110)$ & 1.069 & 0.076 & $0.151(0.089)$ & 1.163 & 0.174 & $0.085(0.090)$ & 1.088 & 0.098 \\
\hline & S\&T & $0.411 * * *(0.068)$ & 1.508 & 0.826 & $0.238 * * *(0.058)$ & 1.268 & 0.478 & $-0.173 * * *(0.049)$ & 0.841 & -0.348 \\
\hline & Nature & $-0.185 * * *(0.039)$ & 0.831 & -0.673 & $-0.021(0.029)$ & 0.979 & -0.076 & $0.164 * * *(0.032)$ & 1.178 & 0.597 \\
\hline & Religion 3 & & & & & & & & & \\
\hline & Atheïst & $-0.143(0.305)$ & 0.867 & -0.069 & $-0.621 *(0.246)$ & 0.538 & -0.298 & $-0.478 *(0.236)$ & 0.620 & -0.229 \\
\hline & Spiritual & $-0.141(0.300)$ & 0.868 & -0.063 & $-0.272(0.251)$ & 0.762 & -0.122 & $-0.131(0.234)$ & 0.877 & -0.059 \\
\hline & Familiarity & $-1.160 * * *(0.265)$ & 0.313 & -0.549 & $-0.971 * * *(0.206)$ & 0.379 & -0.459 & $0.190(0.222)$ & 1.209 & 0.090 \\
\hline
\end{tabular}

$* p<0.05, * * p<0.01, * * * p<0.001$

Note: Multinomial logistic regression $(N=750)$. M (=Model), IV (=Independent variable), $B=$ unstandardized logistic coefficients, $B s^{\prime}=$ partially standardized logistic coefficients, ref. category gender = male; ref. category familiarity $=$ familiar, ref. category Religion 3 = belief in God, S\&T = attitudes toward science and technology

Further, people who are familiar with nanotechnology seem to be more likely to have a positive attitude toward nanotechnology (model 5). In addition, once familiarity is included in the model, the minor effect of educational background becomes non-significant. In other words, highly educated people are relatively more familiar with nanotechnology (see Table 2), and it is this effect of familiarity that increases the likelihood of having a positive attitude toward nanotechnology, not educational background directly. In addition, familiarity with nanotechnology does not increase the likelihood of being negative rather than neutral (model 5C), indicating the fact that people with negative and neutral attitudes are both relatively unfamiliar with nanotechnology. No significant interaction effects were found between familiarity and religiosity.

The results presented in Table 4 (models 4 and 5) further show that concerns about the changing relationships between nature, technology, and society significantly predict attitudes toward nanotechnology. In particular, whereas more holistic views about the relation between people and the environment increase the likelihood of being negative rather than positive toward nanotechnology $(\operatorname{Exp}(B)=1.20(1 / 0.831)$, more positive views on techno-scientific progress increase the likelihood of being positive rather than negative about nanotechnology by a factor of 1.51 . The strongest correlate of positive versus negative attitudes toward nanotechnology is attitudes toward science and technology $\left(B s^{\prime}=0.826\right)$, followed by nature interference $\left(B s^{\prime}=-0.673\right)$, familiarity $\left(B s^{\prime}=-0.549\right)$, and gender $\left(B s^{\prime}=-0.411\right)$. Finally, the partially standardized logit coefficients also suggest that, while the likelihood of having a positive attitude toward nanotechnology seems to correlate most strongly with positive attitudes toward science and technology, the likelihood of having a negative attitude associates most strongly with ecocentric values. 


\section{Discussion}

In this article, findings were reported from one of the first surveys regarding public perceptions about nanotechnology in Germany. By using stepwise logistic regression analyses, this study was able to examine the role of familiarity with nanotechnology and heuristics, as well as to consider the moral covariates of nanotech attitudes. Consistent with previous research (Cobb and Macoubrie 2004; Lee et al. 2005; Waldron et al. 2006; Kahan et al. 2009), the analyses first showed that a majority of the people are still not familiar with nanotechnology. Moreover, this study adds to these results that women and people with a relatively lower educational background are least informed about nanotechnology. Further, this study has shown that most people in Germany have an indifferent, ambiguous, or non-attitude toward nanotechnology. This contrast with previous US studies which has shown that people perceive the benefits of nanotechnology as higher than the risks (Cobb and Macoubrie 2004). Based on these data it should not come as a surprise that future opposition toward nanotechnology in Germany may be stronger than what is currently expected.

Further, at the explanatory level, this study shows that nanotech familiarity is an important correlate of attitudes toward nanotechnology. This is consistent with previous research that has shown that people's self-estimated knowledge is positively related to riskbenefit trade-offs (Cobb and Macoubrie 2004). It could be argued then that the significant effect of selfestimated knowledge about nanotechnology on attitudes is in accordance with the familiarity hypothesis (i.e., the assumption than support for new technologies is positively related with familiarity). However, consistent with the experimental study by Kahan et al. (2009), our findings suggest that a pro-science and technology orientation can predispose people to learn more about nanotechnology. Further, in a study by Scheufele and Lewenstein (2005) it was shown that there is no relation between actual (rather than self-reported) knowledge and nanotech attitudes. In addition, in the latter study it was shown that the positive relation between media use and nanotech attitudes are not mediated by scientific literacy. Therefore, it might be useful for future models on nanotech attitudes to include media-related variables, cultural predispositions, as well as self-estimated and actual knowledge.

Furthermore, this study has shown that normative thoughts about techno-scientific progress on the one hand, and views on human interference with the natural order on the other hand, are of major importance to understand people's attitudes toward nanotechnology. This is consistent with previous research that has shown that people's understanding of nanotechnology strongly relates to moral outlooks (Pidgeon et al. 2009; Kahan et al. 2009). In other words, the co-existing role of the rational (self-reported familiarity) and the trans-rational (moral outlooks) may necessitate a post-normal science and new ways of public participation rather than one-way risk communication (Funtowicz and Ravetz 1992). However, we acknowledge that experimental research is needed to examine if moral outlooks can also moderate the impact of information exposure on attitudes toward nanotechnology in Germany (cf. Kahan et al. 2009). We also acknowledge that future research might benefit from using moral variables which are less proximal to perceptions about nanotechnology (cf. Slovic and Peters 1998; Sjöberg 2003).

Finally, this study shows that religiosity has no or only a marginally significant effect on people's attitudes toward nanotechnology in Germany. People that believe in God are more likely than those that do not to form an opinion about nanotechnology, whether it will be positive or negative. However, belief in God does not differentiate positive and negative attitudes toward nanotechnology. This contrasts with previous US research that has shown that religiosity may act as a perceptual filer and that there exists a weak though significant negative association between support for funding of nanotechnology and levels of religiosity at the individual level (Brossard et al. 2009). Further, whereas the study by Scheufele et al. (2009) found a negative relation between aggregate levels of religiosity and support for nanotechnology at the country-level, this study shows that within a more secularized states like Germany, moral covariates other than religion can replace the "Scientists playing as God" explanation. In other words, although the effect of religiosity on attitudes toward nanotechnology may decrease with levels of secularization, the findings of this study suggest that attitudes toward nanotechnology do also strongly relate to moral issues in more secularized states. 
Moreover, as noted by one of the reviewers, it is likely that the effect of religiosity in a more fully specified model will be completely mediated by moral covariates regardless differences in secularization.

Acknowledgments This article is based on research supported by the German Research Foundation (DFG) and the French National Research Agency (ANR) under Grant No. 07-FRAL-024-0. We wish to thank the two anonymous reviewers for their comments on an earlier draft of this article.

\section{Appendix}

See Table 5.
Table 5 Information on the quota sample: German population and sample $(n=750)$

\begin{tabular}{lrl}
\hline & German population $(\%)$ & Sample $(\%, n)$ \\
\hline Gender & & \\
Male & 51.0 & $51.0(n=382)$ \\
Female & 49.0 & $49.0(n=368)$ \\
Age & & \\
18-24 years & 10.0 & $11.2(n=84)$ \\
25-34 years & 14.5 & $16.0(n=120)$ \\
35-49 years & 29.8 & $33.1(n=248)$ \\
50-64 years & 22.3 & $25.2(n=189)$ \\
65+ & 23.4 & $14.5(n=109)$ \\
Education & & \\
No education & 3.4 & $0.7(n=5)$ \\
Secondary education & 42.8 & $45.7(n=343)$ \\
Vocational or higher education & 28.9 & $27.3(n=205)$ \\
Advanced technical college/university & 24.9 & $26.3(n=197)$ \\
Region & & \\
Baden-Württemberg & 13.0 & $12.4(n=93)$ \\
Bayern & 15.0 & $15.1(n=113)$ \\
Berlin & 4.0 & $3.9(n=29)$ \\
Brandenburg & 3.0 & $3.1(n=23)$ \\
Bremen & 1.0 & $0.8(n=6)$ \\
Hamburg & 2.0 & $2.5(n=19)$ \\
Hessen & 7.0 & $7.5(n=56)$ \\
Mecklenburg-Vorpommern & 2.0 & $1.7(n=13)$ \\
Niedersachsen & 10.0 & $10.1(n=76)$ \\
Nordrhein-Westfalen & 22.0 & $22.7(n=170)$ \\
Rheinland-Pfalz & 5.0 & $4.8(n=36)$ \\
Saarland & 1.0 & $1.1(n=8)$ \\
Sachsen & 5.0 & $5.2(n=39)$ \\
Sachsen-Anhalt & 3.0 & $2.7(n=20)$ \\
Schleswig-Holstein & $3.5(n=26)$ \\
Thüringen & 3.0 & $2.9(n=22)$ \\
\hline & &
\end{tabular}




\section{References}

Agresti A (1996) An introduction to categorical data analysis. Wiley, New York

Ameisen J et al (2007) Ethical issues raised by nanosciences, nanotechnologies and health. Opinion nr. 96, National Consultative Ethics Committee for Health and Life Sciences

Bainbridge W (2002) Public attitudes toward nanotechnology. J Nanopart Res 4:561-570

Brossard D, Scheufele DA, Kim E, Lewenstein BV (2009) Religiosity as a perceptual filter: examining processes of opinion formation about nanotechnology. Public Underst Sci 18(5):546-558

Cobb M, Macoubrie J (2004) Public perceptions about nanotechnology: risk, benefits and trust. J Nanopart Res 6:395405

Corral-Verdugo V, Carrus G, Bonnes M, Moser G, Sinha J (2008) Environmental beliefs and endorsement of sustainable development principles in water conservation. Toward a new human interdependence paradigm scale. Environ Behav 40:703-725

European Commission (2005) Some figures about nanotechnology R\&D in Europe and beyond. http://cordis.europa. eu.int/nanotechnology. Accessed 14 October

Funtowicz S, Ravetz J (1992) Three types of risk assessment and the emergence of post-normal science. In: Krimsky S, Golding D (eds) Social theories of risk. Praeger, London

Heelas P, Woodhead L (2005) The spiritual revolution: why religion is giving way to spirituality. Blackwell, Oxford

Kahan D, Braman D, Slovic P, Gastil J, Cohen G (2009) Cultural cognition of the risks and benefits of nanotechnology. Nat Nanotechnol 4:87-90

Lee C, Scheufele D, Lewenstein B (2005) Public attitudes toward emerging technologies. Sci Commun 27:240-267
Luhmann N (1989) Vertrauen: Ein Mechanismus der Reduction Sozialer Complexität [Trust: a mechanism for the reduction of social complexity]. Enke, Stuttgart

Norris P, Inglehart R (2004) Sacred and secular: religion and politics worldwide. Cambridge University Press, Cambridge

Pidgeon N, Harthorn BH, Bryant K, Rogers-Hayden T (2009) Deliberating the risks of nanotechnologies for energy and health applications in the United States and United Kingdom. Nat Nanotechnol 4(2):95-98

Roco M, Bainbridge W (eds) (2001) Societal implications of nanoscience and nanotechnology. Kluwer, Dordrecht

Rothstein H, Huber M, Gaskell G (2006) A theory of risk colonization: the spiralling regulatory logics of societal and institutional risk. Econ Soc 35(1):91-112

Scheufele D, Lewenstein B (2005) The public and nanotechnology: how citizens make sense of emerging technologies. J Nanopart Res 7:659-667

Scheufele D, Corley E, Shih T, Dalrymple K, Ho S (2009) Religious beliefs and public attitudes toward nanotechnology in Europe and the United States. Nat Nanotechnol 4(2):91-94

Sjöberg L (2000a) Perceived risk and tampering with nature. J Risk Res 3:353-367

Sjöberg L (2000b) Factors in risk perception. Risk Anal 20:1-11

Sjöberg L (2003) Distal factors in risk perception. J Risk Res 6(3):187-211

Slovic P, Peters E (1998) The importance of worldviews in risk perception. Risk Decis Policy 3(2):165-170

Tversky A, Kahneman D (1974) Judgment under uncertainty: heuristics and biases. Science 185:1124-1131

Waldron A, Spencer D, Batt C (2006) The current state of public understanding of nanotechnology. J Nanopart Res 8:569-575

Wolf C (2008) How secularized is Germany? Cohort and comparative perspectives. Soc Compass 55(2):111-126 